\title{
R\&D approach based on multiple partners and Design Thinking, Lean Startup, and Agile concepts: case study in the electricity sector
}

Lorenna Fernandes Leal1, Artur Tavares Vilas Boas Ribeiro ${ }^{2}$ Victor Romão ${ }^{3}$ Guilherme Soares Gurge do Amaral ${ }^{4}$, Ricardo Altmann ${ }^{3}$, Ricardo Kahn ${ }^{4}$, Bruno Guilherme Pacci ${ }^{3}$, Marcos Avó3 ${ }^{\text {, Mario Salerno }}{ }^{1}$ Guilherme Plonski², Eduardo Zancul ${ }^{2}$

${ }^{1}$ University of São Paulo - USP, Production Engineering Department, São Paulo, SP, Brazil.

${ }^{2}$ University of São Paulo - USP, Center for Technology Policy and Management, São Paulo, SP, Brazil.

${ }^{3}$ Lunica, São Paulo, SP, Brazil.

${ }^{4}$ ISA CTEEP, São Paulo, SP, Brazil.

How to cite: Leal, L. F., Ribeiro, A. T. V. B., Romão, V. et al. (2021), “R\&D approach based on multiple partners and Design Thinking, Lean Startup, and Agile concepts: case study in the electricity sector", Brazilian Journal of Operations \& Production Management, Vol. 18, No. 1, e20211024. https://doi.org/10.14488/BJOPM.2021.003

\begin{abstract}
Goal: The paper aims to increase the understanding of the results and challenges that arise when running R\&D projects based on multiple partners and the integration of Design Thinking, Lean Startup, and Agile concepts.

Design / Methodology / Approach: We followed a case study approach in the electricity sector. Two project cases were studied, using triangulated data from interviews, internal documents, and nonparticipant observations.

Results: The results of the Design Thinking, Lean Startup, and Agile concepts application in R\&D projects show improvements in knowledge absorption, solution improvement through collaborative insights between partners, and identification of short-term opportunities. Some challenges, however, were identified, such as noisy integration, the role of the project manager requiring a sophisticated skillset, and complicated decision-making processes.

Limitations of the investigation: The conclusions have the inherent limitations of a case study conducted in one industrial sector and two projects led by one company.

Practical implications: The evolving competitive landscape demands more effective pathways to foster innovation. Recent approaches to innovation have challenged R\&D practices. This study discusses a new way of addressing R\&D efforts with multiple partners by integrating Design Thinking, Lean Startup, and Agile concepts.

Originality / Value: The combined and coherent application of concepts derived from Design Thinking, Lean Startup, and Agile in R\&D practices in the electricity sector is new. The high volume of R\&D activity in the electricity sector makes this in-depth analysis both relevant and valuable.
\end{abstract}

Keywords: R\&D; Electricity Sector; Project Governance; Lean Startup; Agile.

\section{INTRODUCTION}

The electricity sector faces three significant changes due to technology improvements and environmental pressures: decentralization, decarbonization, and digitalization ( $\mathrm{Di}$ Silvestre et al., 2018). The first, decentralization, is about the opportunities that emerge with new technologies capable of generating energy for local communities (e.g., solar energy) and

Financial support: ANEEL R\&D Program has funded this project.

Conflict of interest: The authors have no conflict of interest to declare.

Corresponding author: ezancul@usp.br

Received: 29 June 2020.

Approved: 14 October 2020.

Editor: Osvaldo L. G. Quelhas and Julio Vieira Neto. 
also with new ways of distributing them. The second, decarbonization, is a result of environmental pressures and the economic viability that renewable energy sources bring to the decision-making process of choosing the national energy matrix. The third, digitalization, relates to novel ways of exchanging goods through digital transactions and business models. Therefore, established electricity companies find themselves looking for ways to make these changes and remain competitive.

In this context, a Latin American utility company has designed a novel R\&D approach in Brazil. This approach has three main characteristics: (i) open innovation to develop solutions through external partners; (ii) projects executed by multiple partners arranged in a complementary way, such as universities along with startups; (iii) project management based on concepts derived from Design Thinking, Lean Startup, and Agile (i.e, short cycles iteration, customer involvement, and flexibility around a product vision).

When it comes to new product development, collaboration is often related to quality improvements and reduced time to market (Enrique et al., 2018; Sjoerdsma and Van Weele, 2015). This perception has its roots in results founded on research being made about supplier relationship that presents similar conclusions, as pointed out by Ragatz et al. (2002) when discussing supplier involvement on new product development: "the result is often a better product design that is brought to market faster and ultimately, delivers greater value for the customer" (p.389). In the same way, research on R\&D and new product development has also shown that relying on multiple and diverse partners leads to decreased time to market, better quality and efficiency of innovations, facilitated access to new markets, and improved cooperation and innovation skills (Van Beers and Zand, 2014; Narula, 2001).

In the Brazilian context, the utility company came across several challenges during the first two implementations of the novel approach, such as (i) the role of the project manager; (ii) dealing with different partners' mindsets; (iii) coordinating parts of the project with different technology readiness levels; and (iv) dealing with, and prioritizing, feedbacks from various stakeholders of different areas. From an academic standpoint, these challenges are often called "coordination costs" (Li et al., 2012; Dahlander and Gann, 2010) and could be a result of the complexity brought with the new elements from the newly adopted R\&D approach. Understanding this, we proposed the present research question: What are the main reasons for the challenges that arise when approaching R\&D project management with multiple partners and addressing uncertainties via experimentation, short development cycles, and customer involvement?

The paper is organized as follows. The next section presents the literature on R\&D where there are multiple partners and specific challenges regarding governance. The third section presents the study methodology. The fourth section presents the collected data from the two project cases. The fifth section discusses the results and the last section provides the conclusions of the study.

\section{LITERATURE REVIEW}

\section{Open innovation and R\&D with different knowledge sources}

Since Chesbrough's book proposing the open innovation framework (Chesbrough, 2003a), a lot of attention has been given to the topic as a research field and an opportunity to improve innovation practices (West and Bogers, 2017). According to Chesbrough (2003b), the emergence of the open innovation model came through changes at the end of the 20thcentury innovation scene, such as (i) the rise in the number and mobility of knowledge workers and (ii) the increase in the availability of private venture capital. These changes led to scientists and engineers having a new way to pursue breakthroughs, meaning that "if a company that funded a discovery doesn't pursue it in a timely fashion, the people involved could pursue it on their own - in a startup financed by venture capital" (Chesbrough, 2003b, p.36).

As a consequence, countless innovations came from outside corporation boundaries, requiring new practices to be put in place for accessing strategic breakthroughs. In addition, 
the open innovation framework proposed that, beyond the understanding of new and diverse sources of knowledge, companies could also spin off their innovations in various forms, such as commercializing with other companies, developing new markets, or even creating new startups. Open innovation, in this sense, can be described using the words of Lichtenthaler (2011) as "systematically performing knowledge exploration, retention, and exploitation inside and outside an organization's boundaries throughout the innovation process" (p.77).

Even though Chesbrough's book is considered one of the primary references on the subject, literature around interactions from outside firm boundaries can be traced back decades earlier and some scholars agree that it is not a new approach (Hossain et al., 2016), especially regarding R\&D and its reliance on external partners (Dahlander and Gann, 2010). R\&D partnership diversity is the subject of multiple studies, and usually correlates with innovation outputs (Du et al., 2014; Lavie and Miller, 2008; Laursen and Salter, 2006), being a well-established strategy not only for cost reduction but also for value enhancing, resulting from innovations that, under different circumstances, could not be developed (Martinez-Noya and Narula, 2018). It is relevant to note that, for value enhancement, some authors highlight that companies must be well structured to deal with external innovations, having absorptive capacity, which means "the ability of a firm to recognize the value of new, external information, assimilate it, and apply it to commercial ends" (Cohen and Levinthal, 1990).

R\&D external knowledge sources can be broadly categorized into two groups: sciencebased and market-based (Barbosa, 2018; Gesing et al., 2015; Du et al., 2014). Market-based sources involve for-profit institutions, usually related to industry knowledge such as customers and suppliers. These sources are expected to provide a better understanding of applications, opportunities, and enhance market fit. Science-based sources are usually institutions oriented towards generating and disseminating scientific knowledge, such as universities and research institutions, and are expected to provide value in assessing unique technical knowledge and long-term results due to breakthroughs (Barbosa, 2018; Gesing et al., 2015). Many studies have already highlighted the benefits of engaging with both types of partners jointly (Van Beers and Zand, 2014). Lucena and Roper, 2016, for example, demonstrated the positive results of working with science- and market-based partners, such as an improvement of the contractor ambidexterity capability, meaning the ability to seek radical and incremental innovations at the same time, and absorptive capacity. Other benefits comprise reducing time to market, improving the quality and efficiency of innovations, facilitating access to new markets (Narula, 2001), and also learning further cooperation and innovation skills (Van Beers and Zand, 2014).

On the other hand, relying on a diverse set of external partners is not an easy task, with outcomes ranging from learning benefits to complexity difficulties (Martinez-Noya and Narula, 2018). Dahlander and Gann (2010) highlighted that there are two critical challenges to overcome when dealing with external partners: the costs of coordination and competition.

"Costs of coordination emerge from organizations that are different, where it may be difficult to bridge organizational boundaries. In the openness literature, maintaining too many relationships is costly and may lead to a diversion of managerial attention. There are also costs of competition that emerge from the risk that one actor would act opportunistically in bad faith. Another potential cost is related to protecting ideas to which others have access." (Dahlander and Gann, 2010, p.706)

Coordination costs build up with the increase in complexity and diversity of the partners (Li et al., 2012). Morandi (2013) argued that, to deal with diverse partners, companies must invest more in planning activities than they usually do for internal R\&D processes. This cost relates to avoiding misunderstandings, misalignments, low commitment, and other problems caused by the differences in partners' cultural backgrounds (especially when connecting partners from industry and academia). 


\section{R\&D governance with multiple partners}

Answering the challenges around complexity, scholars have pointed out the importance of governance structures. The premise is that governance mechanisms can influence the partners' behavior, enhancing collaboration and minimizing opportunistic behavior (Barbosa, 2018; Gesing et al., 2015). Gesing et al. (2015) presented the concept of collaboration governance - the arrangement of governance mechanisms in the context of multiple partners - playing a critical role in the open innovation literature, albeit less explored.

The concept of governance emerged as a way to protect investors from the possible misuse of their investments by companies' administrators, avoiding expropriations, and other opportunistic behaviors (Shleifer and Vishny, 1997). To this end, companies started to create processes, structures, roles, and other mechanisms to guarantee accountability to its stakeholders in general. In the context of R\&D and New Product Development, primarily related to the concept of project governance, Sommer et al. (2014) presented governance as "a set of management systems, rules, protocols, relationships, and structures that provides the framework within which decisions are made to achieve the intended business or strategic motivation" (p.185). For Gesing et al. (2015), on R\&D alliances, "an effective governance mode is one that minimizes transaction costs while maximizing value-creation incentives" (p.427).

Reinforcing the arguments made by Gesing et al. (2015), Li et al. (2012) highlighted that a rise in the partnership's complexity can lead to knowledge exchange difficulties, affecting the choice of the governance structure. According to the authors, increasing the number of partners widens the organizational differences between them, making integrative mechanisms - such as meetings and personal interactions - more challenging to implement. Barbosa (2018) presented the fact that different studies found similar inverted U-shaped curves when analyzing R\&D alliance characteristics around the complexity of partners, meaning that, although more partners can bring benefits, a higher number can lead to managerial problems.

\section{METHODOLOGY}

It has been pointed out that orchestrating multiple and diverse partners is relevant, even though the issue has not been completely explored in the literature (Li et al. 2012; Van Beers and Zand, 2014). Therefore, this paper aims to explore the implications of a new R\&D model based on alliances with multiple and diverse partners. This paper follows a qualitative approach, discussing two case studies of R\&D projects from a Latin American utility company. Data was collected through (i) in-depth interviews with project managers, participants, and the company's representatives; (ii) observatory participation in meetings and workshops; (iii) onsite visits; and (iv) analysis of internal documents.

In-depth interviews, each lasting about 110 minutes, were conducted with 12 stakeholders, from different departments of the utility company and also from the partners involved. Data was gathered during interviews conducted in November 2018 and in February 2019. The research methodology was based on Eisenhardt (1989) and employed a multiple investigator approach, with different teams running interviews and analysis to seek different points of view and more fruitful conclusions. According to Eisenhardt:

"The convergence of observations from multiple investigators enhances confidence in the findings. Convergent perceptions add to the empirical grounding of the hypotheses, while conflicting perceptions keep the group from premature closure. Thus, the use of more investigators builds confidence in the findings and increases the likelihood of surprising findings." (Eisenhardt, 1989, p. 538)

The non-participant observations were based on the researchers' presence in six project meetings, one public event, and some field visits, along with the interviews and meetings. Additionally, the utility company provided internal documents for analysis. 


\section{CASE STUDIES AND RESULTS}

The challenges and opportunities that arise from the use of alliances with multiple and diverse partners are explored through two case studies. The cases are different R\&D projects from the same company operating in a highly regulated sector in Brazil. The company is one of the country's leading private power transmission enterprises, transmitting about $25 \%$ of the energy generated in Brazil, $60 \%$ of the energy consumed in the south-east region, and almost all of the energy in the state of São Paulo.

Aiming to foster innovation in the electricity sector in Brazil, a legal mechanism was developed that made it mandatory to invest $1 \%$ of companies' annual net revenues in R\&D and efficiency improvement (Jannuzzi, 2005). As a consequence, companies have adopted mechanisms to meet their legal obligations and to avoid regulatory risks (Cominato Boer et al., 2014). Recently, owing to competitive pressures in the electricity sector, companies have been improving their R\&D projects to become more innovative and to prepare themselves for a future of even greater competition.

The utility company considered in this study decided to move from the bilateral approach it had taken to this point and to invest in multilateral alliances with complementary profile partners, generally universities and service companies such as consulting firms, startups, and IT firms. Instead of trying to benefit from the strengths of each partner separately in different projects, the utility company opted for projects with multiple partners, taking a close collaboration approach with mutual influences and potential advantages for all parties. The characteristics of the sector means that there are opportunities for close collaboration, since companies do not need to protect themselves from knowledge leakages that could result in new competitors (Martinez-Noya and Narula, 2018; Li et al., 2012). The sector's regulator also encourages knowledge sharing for the industry through publications, events, and workshops.

The increase in the number of partners resulted in an increase in complexity for the projects. In addition, the company had concerns regarding the duration of its R\&D projects. It considered that projects were taking too long to be completed and this was affecting opportunities to enhance the projects' market orientation. The company intended to strengthen its knowledge absorption from the R\&D projects. Inspired by Design Thinking, Lean Startup, and Agile concepts, and due to the exploratory nature of both projects, the company approached these challenges by utilizing short cycles of development with continuous participation and feedback from the company in the two projects. Autonomy for smaller decisions was given to the partners and interaction with the operational level of the company was encouraged. Creative tools were applied, and testing and prototyping were supported by the company. Monthly meetings with all partners and stakeholders were held, as well as monitoring meetings separately with each partner.

\section{Case 1: using drones for the maintenance and inspection of power transmission lines and electricity towers}

The first analyzed case study is an R\&D project intended to identify possible applications and develop drone usage for the maintenance and inspection of power transmission lines and electricity towers. The main goals were to improve efficiency through cost reduction and increase quality in maintenance and inspection routines.

The company selected two partners for this project: a research laboratory specialized in computer vision and artificial intelligence in the electrical engineering department of a renowned university; and a drone distributor and service provider company, with market experience and well-known equipment partners. The electricity company allocated one electrical engineer and the maintenance department coordinator to follow the project and provide feedback, field visits, access to employees, day-to-day routines, and perform test fields with the two partners. The company also hired an external project manager with business and product development knowledge from a consulting firm specialized in tools for creativity and innovation. In addition, two executives from the internal innovation department were responsible for monitoring the project, providing feedback and taking part in more strategic decisions. Table 1 summarizes the scope and participants of Case 1. 
Table 1: Case 1 - scope and participants

\section{Case 1 - Drones for maintenance and inspection}

\begin{tabular}{|c|c|c|c|}
\hline \multicolumn{4}{|c|}{$\begin{array}{l}\text { Project scope: To investigate and develop applications of drones for the maintenance and } \\
\text { inspection of power transmission lines. }\end{array}$} \\
\hline Stakeholder & Type & Expertise & Role \\
\hline $\begin{array}{l}\text { Research laboratory from } \\
\text { the electrical engineering } \\
\text { department of a renowned } \\
\text { university }\end{array}$ & Partner & $\begin{array}{l}\text { Computer vision and } \\
\text { artificial intelligence }\end{array}$ & $\begin{array}{c}\text { Develop solutions related to } \\
\text { the software and operating } \\
\text { algorithms }\end{array}$ \\
\hline $\begin{array}{l}\text { Drone distributor and } \\
\text { service provider company }\end{array}$ & Partner & $\begin{array}{l}\text { Market experience and } \\
\text { well-known equipment } \\
\text { partners }\end{array}$ & $\begin{array}{l}\text { Develop solutions related to } \\
\text { hardware and drone piloting }\end{array}$ \\
\hline $\begin{array}{l}\text { Consultant from a firm } \\
\text { specialized in tools for } \\
\text { creativity and innovation }\end{array}$ & Project manager & $\begin{array}{l}\text { Business and product } \\
\text { development knowledge }\end{array}$ & $\begin{array}{l}\text { Manage the project and to } \\
\text { be the link between the } \\
\text { project and the company's } \\
\text { internal innovation } \\
\text { department }\end{array}$ \\
\hline $\begin{array}{l}\text { Maintenance department } \\
\text { (the coordinator and one } \\
\text { engineer) }\end{array}$ & $\begin{array}{l}\text { Departments } \\
\text { benefiting from } \\
\text { the project }\end{array}$ & $\begin{array}{l}\text { Maintenance and } \\
\text { inspection routines }\end{array}$ & $\begin{array}{l}\text { Follow the project and } \\
\text { provide feedback, field visits, } \\
\text { access to employees, day-to- } \\
\text { day routines, and perform } \\
\text { field tests with the partners }\end{array}$ \\
\hline $\begin{array}{l}\text { Innovation department } \\
\text { (two executives) }\end{array}$ & $\begin{array}{l}\text { Responsible for } \\
\text { the R\&D projects }\end{array}$ & Manage the R\&D projects & $\begin{array}{l}\text { Monitor the project, provide } \\
\text { feedback and take part in } \\
\text { more strategic decisions }\end{array}$ \\
\hline
\end{tabular}

At the beginning of the project, a few exploratory activities were held: desk research on the newest trends and applications of drones, both in the electricity sector and in other industries; tests with drones for different opportunities of inspection and maintenance activities; experiments with different drones to understand how different models are able to capture images and the image resolution needed, etc. Brainstorming sessions were held, with all the stakeholders present, making use of creativity tools. This exploratory phase was beneficial for collecting insights from different points of view, that is: the long-term view from the university, the market view from the drone distributor, the routine view from the employees of inspection and maintenance, and also the strategic view from the innovation department. After a few iterations, the drone model and its application on inspection and maintenance were selected. The selected application was to make use of computer vision for the inspection of towers and sub-stations to identify the presence of vegetation, defects, and damages. In order to simplify the use of drones for maintenance and inspection employees, software for flight automation was idealized. This way, the drone would be able to identify by itself the points of inspection and fly in an automated mode, while the employee would supervise and act when necessary. Following this exploratory phase, the university became responsible for the software development, and the drone distributor remained accountable for testing and flying the drones for inspection and maintenance activities, including beyond the applications expected for the software. At this point, the two partners started to work separately, with different activities each, but still in an interdependent way. The monthly meetings helped to provide alignment between the partners, but information was also shared between the partners out of meetings.

One example of how having multiple partners added value to this project is the drone selection. Initially, through desk research, it was found that the drone model necessary to collect images with good-enough quality would be both large and expensive. The company, then, started a purchase process for a few of these drones. At the same time, seven flight protocols and 25 different drones were tested by the drone distributor, and the images collected were analyzed by the university. The tests resulted in the discovery that the best drone model is a smaller one, which is also 30 times less expensive. The company stopped the 
purchase process of the large model and purchased a few smaller drones. If the partnership had not been established, the university would not have been able to run such a high number of tests, with several different models. The drone distributor, in its turn, lacked the competence to analyze the applicability of the images without external support.

An additional advantage found by the company was the portability of the newly selected drone. As it is easier to carry, the drone could be better disseminated along with the several inspection and maintenance teams across the country. The utility company benefited from the knowledge and economy generated by this discovery, not only from the purchase but also by not spending time and resources trying to adapt to a drone model that was not suitable for the intended purpose. The drone distributor worked very closely with the maintenance department, collecting feedback, generating knowledge and also transferring its knowledge and skills to the employees through workshops. This close relationship between the two parties helped to build trust, which was also extended to the innovation department.

Another example of how having multiple partners added value to this project is the software development. The university developed and frequently tested the application jointly with an employee from the maintenance department. According to interviews with both the university and the utility company, the delivery of software functions and tests with the user happened at a much higher pace than in previous similar projects. This could evidence the influence of the adopted development approach of short development cycles. After the primary tests of the application features performed by the university, the drone distributor performed field experiments and collected data for computer vision development. One aspect highlighted by the interviewees was that the drone distributor provided the market and business view for the project team.

However, despite the above-mentioned benefits, the integration and management of the project were not straightforward. In the first months, the two partners with their different cultures and working methods, compelled to work together with a broad objective, did not have an easy integration. The drone distributor saw the university as too theoretical, not "going to the field" enough. The university, on the other hand, was not used (i) to working so closely with internal departments, (ii) to testing and delivering continually and (iii) did not engage enough with the employees of the maintenance department. The drone distributor was more open to experimentation and attending to demands from the maintenance department. The drone distributor also demonstrated it was not restricted to the scope defined by the contract, as they saw the project as an opportunity to learn and find ways to apply the use of a drone, which could expand its market. The relationship and partnership with the utility company were also strategic because it helped the drone distributor grow its brand. The university, due to its nature, needed to be more concerned with the limits of the contract scope and formal procedures. It mostly waited for the monthly meetings to present its advances and collect feedback from the innovation department executives. The university saw the drone distributor as not having focus because it accepted so many demands from the maintenance department and it also complained about tests that were not precisely performed, not collecting data as expected.

After a few months, the innovation department found that the external project manager role was not fully effective in dealing with the alignment of expectations and in the mediation of conflicts. Whilst his expertise in specific innovation and creativity tools meant that the project manager was helpful at the beginning, in the exploratory activities, going forward, his role was less useful. As a result, project management, mediation, and alignment were absorbed by the innovation department executives after the exploratory phase. During the interviews, many stakeholders highlighted that, because of the several participants, the initial project manager, the employees of maintenance department, and the executives of the innovation department, there were some difficulties with decision-making processes, since roles were not clearly defined at the beginning. Initially, the close relationship of the drone distributor with the maintenance department employees and the innovation department executives pushed project decisions to operational and short-term applications. The lack of managerial practices, along with different types of partner engagement, could be, therefore, one reason for shortcomings in partners integration. 


\section{Case 2: software development for mapping and supervising power transmission line corridors}

The second case study is an R\&D project intended to develop a geoprocessing software for the mapping and supervision of power transmission line corridors, and also to generate solutions for social and/or commercial exploitation of these areas. The project aimed to automate inspection activities using satellite images, crossing this information to socioeconomic data, and thus classifying the risk of land invasion for each region of the power transmission line. In addition, it was expected to find inventive ways to make use of the power transmission line corridor to avoid land invasions, using geographic and socioeconomic data.

The company selected four partners for this project: (i) a company specialized in geoprocessing software; (ii) a non-profit research group specialized in natural resources study and research; (iii) a research group specialized in environmental management and geotechnology from the Center of Natural Sciences Department of a renowned university; and (iv) a consulting firm specialized in innovation and sustainable development. The main point of contact for the partners in the utility company was one executive from the environment department. The leading executive from the consulting firm, having previous experience in $R \& D$ projects in the Brazilian energy sector, was selected to work as the project manager. The same two executives from the innovation department of the first case study were also responsible for monitoring the project, providing feedback and taking part in strategic decisions. Table 2 summarizes the scope and participants of Case 2.

Table 2: Case 2 - scope and participants

\begin{tabular}{cccc}
\hline \multicolumn{2}{c}{ Case 2 - Software for supervising power transmission lines } \\
\multicolumn{2}{c}{ Project scope: To avoid land invasions and automate the supervision of power transmission line } \\
corridors.
\end{tabular}

Each of the partners had one main responsibility in the project. The research group from the university was responsible for developing a change detection algorithm in order to identify the 
probability of land invasion in the transmission line corridor by analyzing satellite images, and also for crossing the information with socioeconomic and geographic data. The change detection algorithm would then be used in the software to monitor corridors and automatically send alerts of areas that needed intervention due to the high risk of invasion. The software architecture was the responsibility of the company specialized in geoprocessing software. These two partners were, in consequence, very dependent on each other. The non-profit research group was responsible for collecting information related to the socioeconomic and geographical conditions of the transmission line corridor. This information would then be used as input for the monitoring software, and would also contribute to understanding the behavior and conditions of the population near the transmission line corridor and the motivations for land invasions. Data processing and understanding the behavior and conditions of this population were the responsibility of the consulting firm specialized in innovation and sustainable development. These last two companies were, therefore, interdependent. The multiple responsibilities and skills needed for this project demonstrate the complexity level of partners' complementarity. Some degree of concurrent skills and knowledge were also present.

Similarly to the first case study, the initial few months of the project were dedicated to exploratory activities, such as: desk research on existing solutions; visits to critical areas of the transmission line corridor; shadowing employees currently handling inspections and maintenance; interviewing employees from the legal and socioenvironmental solutions departments; collecting public socioeconomic and geographical information from the transmission line corridor area. The consulting firm applied Design Thinking tools to understand the reasons behind the land invasions that occur in the transmission line corridor. Meetings between the geoprocessing software company and the research group from the university were held in order to build an early software architecture. Following this exploratory phase, a workshop was held. Approximately 30 people took part in the workshop, including many of the stakeholders from the four partners and employees from the utility company, as well as external participants that were not directly working on the project. The workshop started with each of the partners presenting the main results and insights from the exploratory phase. After this, the participants were invited to sit in groups and generate application ideas for the social and commercial use of the transmission line corridor area. These ideas were later analyzed concerning the legal, economic and technological feasibility aspects of their application.

The workshop is an example of how to absorb not only the partners' and employees' potential ideas but also the creativity and different perceptions of the problem from the network of partners. According to interviews, one of the most creative ideas was given by an external participant. Additionally, training on the Geoprocessor Software was provided to many project participants, in order to align all the stakeholders regarding one main output expected from the project. Interactions between the project partners, for instance, supported the identification of software features already provided by the market, directing the university to focus its efforts on developing a new algorithm to support the classification of land invasions types.

Owing to the higher number, the integration of partners was even more challenging than in the previous case. The use of an external project manager was proven not to be sufficient. Additionally, since the chosen project manager was also a key member of one of the partners, it was difficult to establish a leadership role among the other partners. For this reason, the innovation department executives absorbed the management, mediation and alignment roles. As in the previous case, interactions between all the partners did not happen frequently, but partners interacted with each other bilaterally, especially the geoprocessing software company and the research team from the university, because of the nature of their work. The non-profit research group was also important for the algorithm and the database architecture development.

Overlaps of the partners' responsibilities were found and these created confusion among the participants. In contrast to the first case where employees of the maintenance department were found to be very open to new ideas, interviewees in Case 2 saw the company's internal team as having a more traditional approach to business. Other departments (legal and property security, and sustainability) were also invited to participate, providing their views of the solutions being generated. The variety of different interlocutors was seen to confuse the final decision-making process. The participants missed the presence of a project manager to 
have the final say. Another point of interference in the project was the pressure put on delivering results and sticking to a schedule, as a result of the project being part of the strategy of the company. A few interviewees also suggested that the partners did not all need to start in the project at the same time, mainly because the data collection was performed by the nonprofit research group, and the causes of land invasions by the consulting firm, and this information served as input for the other partners. This meant that some of the partners could not begin their work immediately, resulting in some inertia at the beginning of the project.

\section{DISCUSSION}

Evidence from both projects signaled the perception of improvements, compared to previous similar projects the interviewees took part in, including an increase in the rate of deliverables and the pace of the project. Whilst these two projects had not been totally concluded by the time of the main interviews, the quality of the solutions proposed was also classified as having better fit and applicability in comparison to previous R\&D projects. The utility company had already absorbed some intermediary results and knowledge generated, which was very unusual in previous R\&D projects. One spin-off project derived from one of the cases, a center for inspection through image processing and computer vision, was being structured. The interviewees also believed that the partners influenced each other in positive ways.

From the standpoint of governance, in both projects, despite having complementary skills and capabilities, integration between partners was noisy and especially difficult at the beginning. The project managers were not able to provide the required conflict resolution and project management to deal with these difficulties. Therefore, the utility company absorbed the project management role in both cases. Even though the meetings with all partners in both projects helped to align the participants, some interviewees pointed out that there was a need for better-structured meetings. The decision-making process was confusing in both projects, due to the variety of interlocutors. The close relationship between operational areas caused some bias in decision-making, giving priority to short- over long-term strategic solutions. As a result of the experiences from the two cases, for future projects, the company intends to make use of project managers internal to the company.

The use of creativity tools, testing, and prototyping, as well as the exploratory phase at the beginning of the project, were essential for absorbing and capitalizing the different views and knowledge from the partners. The results found could not have been achieved without the partners' collaboration, and this finding confirms the potential of accessing external knowledge to develop innovations through R\&D alliances that could not be achieved internally, as stated by Martinez-Noya and Narula (2018). Along with the workshops held and the close collaboration with operational areas, these approaches also enabled the utility company to improve its absorptive capacity by recognizing the value and assimilating the external information (Cohen and Levinthal, 1990). Figure 1 presents the partners main roles observed in the two case projects.

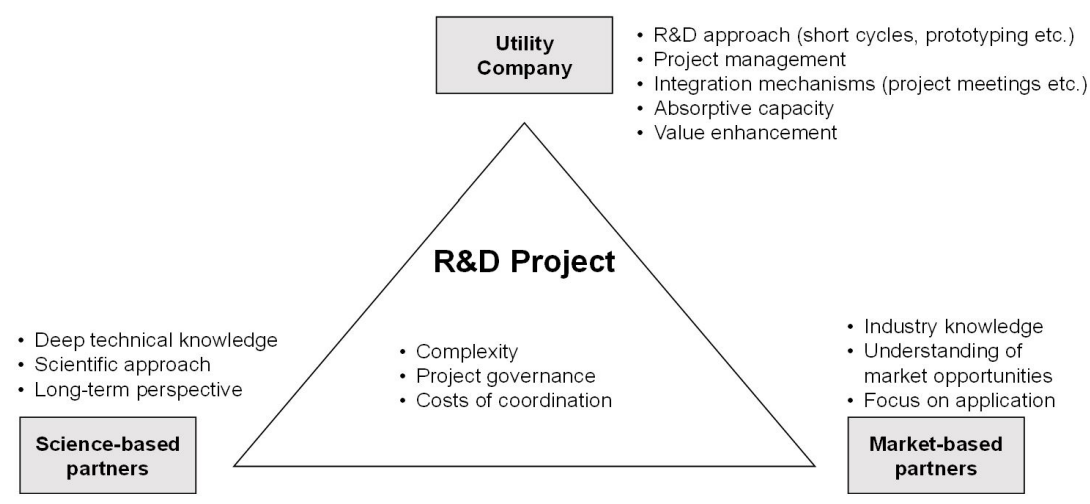

Figure 1. Main partners' roles in the R\&D approach with multiple partners in the electricity sector.

Source: the authors 
The benefits of engaging with science-based partners, with a long-term view, and the development of technology- and market-based partners, with broader market views, were also observed (Barbosa, 2018; Gesing et al., 2015; Van Beers and Zand, 2014; Lucena and Roper, 2016; Narula, 2001). The increase of complexity and coordination costs due to the diverse partners was also verified (Li et al., 2012); but, as stated by Van Beers and Zand (2014), the collaboration activities from these cases might also enhance the capacity of the company to develop and manage future collaborative efforts.

\section{CONCLUSION}

This paper contributes to the literature on R\&D alliances by deepening the understanding of the relationships between different partners, especially from different types, such as science-based and market-based. Following the suggestion in the work of Van Beers and Zand (2014), this paper also contributes to the literature by proposing new schemes for managing R\&D with multiple partners - in our case, by using approaches usually embraced by startups, such as developing solutions through iterations with continuous feedback from final users. Practitioners can benefit from this paper by looking through the details of the steps taken and from the challenges that emerged. Industries that have less competition and can enjoy closer arrangements, owing to the lack of opportunistic behavior and intellectual property leakage risks, could also benefit from these results.

Future studies could collect more data around new strategies for dealing with multiple partners, creating a better understanding of what strategy works best in the context of science- and market-based partners operating together. In this respect, questions for future works could be: What specific routines could lead to a better collaboration between scienceand market-based partners?; How do new project management approaches (such as Lean Startup and Agile) contribute to coordination between multiple partners in R\&D projects?; How do personal behaviors affect the effectiveness of R\&D projects where there are multiple partners?; Which new incentive models could benefit such different stakeholders working in a specific R\&D project?

\section{REFERENCES}

Barbosa, A.P.F.P.L. (2018), Managing Collaborative R\&D Projects with Different Types of Knowledge Sources, Doctoral Thesis, University of São Paulo, São Paulo, Brazil.

Chesbrough, H. (2003a). Open Innovation: The New Imperative for Creating and Profiting from Technology. Harvard Business School Press, Boston, MA.

Chesbrough, H. (2003b), "The era of open innovation", MIT Sloan Management Review, No. Spring, pp. 35-6.

Cohen, W.M. and Levinthal, D.A. (1990), "Absorptive capacity: a new perspective on learning and innovation", Administrative Science Quarterly, Vol. 35, No. 1, pp. 128-52. http://dx.doi.org/10.2307/2393553.

Cominato Boer, D., Salles-Filho, S.L. and Bin, A. (2014), "R\&D and innovation management in the Brazilian electricity sector: The regulatory constraint", Journal of Technology Management \& Innovation, Vol. 9, No. 1, pp. 44-56. http://dx.doi.org/10.4067/S0718-27242014000100004.

Dahlander, L. and Gann, D.M. (2010), "How open is innovation", Research Policy, Vol. 39, No. 6, pp. 699709. http://dx.doi.org/10.1016/j.respol.2010.01.013.

Di Silvestre, M.L., Favuzza, S., Sanseverino, E.R. et al. (2018), "How Decarbonization, Digitalization and Decentralization are changing key power infrastructures", Renewable \& Sustainable Energy Reviews, Vol. 93, pp. 483-98. http://dx.doi.org/10.1016/j.rser.2018.05.068.

Du, J., Leten, B. and Vanhaverbeke, W. (2014), "Managing open innovation projects with science-based and marketbased partners", Research Policy, Vol. 43, No. 5, pp. 828-40. http://dx.doi.org/10.1016/j.respol.2013.12.008.

Eisenhardt, K.M. (1989), "Building theories from case study research", Academy of Management Review, Vol. 14, No. 4, pp. 532-50. http://dx.doi.org/10.5465/amr.1989.4308385.

Enrique, D.V., Ayala, N.F., Lima, M.J.D.R.F. et al. (2018), "The use of ICT tools to support collaborative product development activities: evidences from Brazilian industry", Production, Vol. 28, e20170099 
Gesing, J., Antons, D., Piening, E.P. et al. (2015), "Joining forces or going it alone? On the interplay among external collaboration partner types, interfirm governance modes, and internal R\&D", Journal of Product Innovation Management, Vol. 32, No. 3, pp. 424-40. http://dx.doi.org/10.1111/jpim.12227.

Hossain, M., Islam, K.Z., Sayeed, M.A. et al. (2016), "A comprehensive review of open innovation literature", Journal of Science \& Technology Policy Management, Vol. 7, No. 1, pp. 2-25. http://dx.doi.org/10.1108/JSTPM-02-2015-0009.

Jannuzzi, G.D.M. (2005), "Power sector reforms in Brazil and its impacts on energy efficiency and research and development activities", Energy Policy, Vol. 33, No. 13, pp. 1753-62. http://dx.doi.org/10.1016/j.enpol.2004.02.015.

Laursen, K. and Salter, A. (2006), "Open for innovation: the role of openness in explaining innovation performance among UK manufacturing firms", Strategic Management Journal, Vol. 27, No. 2, pp. 131 50. http://dx.doi.org/10.1002/smj.507.

Lavie, D. and Miller, S.R. (2008), "Alliance portfolio internationalization and firm performance", Organization Science, Vol. 19, No. 4, pp. 623-46. http://dx.doi.org/10.1287/orsc.1070.0341.

Li, D., Eden, L., Hitt, M.A. et al. (2012), "Governance in multilateral R\&D alliances", Organization Science, Vol. 23, No. 4, pp. 1191-210. http://dx.doi.org/10.1287/orsc.1110.0671.

Lichtenthaler, U. (2011), "Open innovation: Past research, current debates, and future directions", The Academy of Management Perspectives, Vol. 25, No. 1, pp. 75-93. http://dx.doi.org/10.5465/AMP.2011.59198451.

Lucena, A. and Roper, S. (2016), "Absorptive capacity and ambidexterity in R\&D: Linking technology alliance diversity and firm innovation", European Management Review, Vol. 13, No. 3, pp. 159-78.

Martinez-Noya, A. and Narula, R. (2018), "What more can we learn from R\&D alliances? A review and research agenda", Business Research Quarterly, Vol. 21, No. 3, pp. 195-212. http://dx.doi.org/10.1016/j.brq.2018.04.001.

Morandi, V. (2013), "The management of industry-university joint research projects: how do partners coordinate and control R\&D activities", The Journal of Technology Transfer, Vol. 38, No. 2, pp. 69-92. http://dx.doi.org/10.1007/s10961-011-9228-5.

Narula, R. (2001), "Choosing between internal and non-internal R\&D activities: Some technological and economic factors", Technology Analysis and Strategic Management, Vol. 13, No. 3, pp. 365-87. http://dx.doi.org/10.1080/09537320120088183.

Ragatz, G.L., Handfield, R.B. and Petersen, K.J. (2002), "Benefits associated with supplier integration into new product development under conditions of technology uncertainty", Journal of Business Research, Vol. 55, No. 5, pp. 389-400.

Shleifer, A. and Vishny, R.W. (1997), "A survey of corporate governance", The Journal of Finance, Vol. 52, No. 2, pp. 737-83. http://dx.doi.org/10.1111/j.1540-6261.1997.tb04820.x.

Sjoerdsma, M. and Van Weele, A.J. (2015), "Managing supplier relationships in a new product development context", Journal of Purchasing and Supply Management, Vol. 21, No. 3, pp. 192-203.

Sommer, A.F., Dukovska-Popovska, I. and Steger-Jensen, K. (2014), "Agile product development governance: on governing the emerging scrum/stage-gate hybrids", in IFIP International Conference on Advances in Production Management Systems, Springer, Berlin, Heidelberg, pp. 184-91. http://dx.doi.org/10.1007/978-3-662-44739-0_23

Van Beers, C. and Zand, F. (2014), "R\&D cooperation, partner diversity, and innovation performance: An empirical analysis", Journal of Product Innovation Management, Vol. 31, No. 2, pp. 292-312. http://dx.doi.org/10.1111/jpim.12096.

West, J. and Bogers, M. (2017), "Open innovation: current status and research opportunities", Innovation, Vol. 19, No. 1, pp. 43-50. http://dx.doi.org/10.1080/14479338.2016.1258995.

Author contributions: Data collection, analysis and writing: Lorenna Fernandes Leal; Artur Tavares Vilas Boas Ribeiro; Eduardo Zancul. Data collection, analysis and paper review: Victor Romão; Bruno Guilherme Pacci; Ricardo Altmann. Analysis, project review, project management and paper review: Guilherme Soares Gurgel do Amaral; Ricardo Kahn; Marcos Avó; Mario Salerno; Guilherme Plonski. 